\title{
Incubation of Methamphetamine but not Heroin Craving After Voluntary Abstinence in Male and Female Rats
}

\author{
Marco Venniro', Michelle Zhang', Yavin Shaham ${ }^{*, 1}$ and Daniele Caprioli, \\ 'Behavioral Neuroscience Research Branch, Intramural Research Program, NIDA, NIH, Baltimore, MD, USA
}

\begin{abstract}
We recently introduced an animal model of incubation of methamphetamine craving after choice-based voluntary abstinence in male rats. Here we studied the generality of this phenomenon to (I) female rats, and (2) male and female rats with a history of heroin self-administration. We first trained rats to self-administer palatable food pellets for 6 days ( $6 \mathrm{~h}$ per day) for either methamphetamine $(0.1 \mathrm{mg} / \mathrm{kg} /$ infusion) or heroin $(0.1 \mathrm{mg} / \mathrm{kg} /$ infusion) for 12 days $(6 \mathrm{~h} /$ day $)$. We then assessed relapse to drug seeking under extinction conditions after I and $2 \mathrm{l}$ abstinence days. Between tests, the rats underwent either voluntary abstinence (achieved via a discrete choice procedure between drug and palatable food; 20 trials/day) or home-cage forced abstinence. We found no sex differences in methamphetamine self-administration or in the strong preference for the palatable food over methamphetamine during the choice-based voluntary abstinence. In both sexes, methamphetamine seeking in the relapse tests was higher after 2 I days of either voluntary or forced abstinence than after I day (incubation of methamphetamine craving). We also found no sex differences in heroin self-administration or the strong preference for the palatable food over heroin during the choice-based voluntary abstinence. However, male and female rats with a history of heroin self-administration showed incubation of heroin craving after forced but not voluntary abstinence. Our results show that incubation of methamphetamine craving after voluntary abstinence generalizes to female rats. Unexpectedly, prolonged voluntary abstinence prevented the emergence of incubation of heroin craving in both sexes.

Neuropsychopharmacology (2017) 42, II26-II35; doi:I0.I038/npp.20I6.287; published online 25 January 2017
\end{abstract}

\section{INTRODUCTION}

Relapse to heroin or methamphetamine use can occur after prolonged abstinence and is often precipitated by exposure to drug-associated cues (Hunt et al, 1971; O'Brien et al, 1992; Rawson et al, 2004; Wikler, 1973). Based on their clinical observations, Gawin and Kleber (1986) proposed that cueinduced cocaine craving increases during early abstinence and remains elevated for extended time periods. An analogous phenomenon termed 'incubation of drug craving' has been observed in rats and mice trained to self-administer cocaine (Grimm et al, 2001; Mead et al, 2007; Neisewander et al, 2000) and rats trained to self-administer alcohol (Bienkowski et al, 2004), nicotine (Abdolahi et al, 2010; Funk et al, 2016), heroin (Fanous et al, 2012; Shalev et al, 2001), and methamphetamine (Li et al, 2015; Shepard et al, 2004). In animal models, incubation of drug craving refers to the time-dependent increase in drug seeking during forced abstinence (Pickens et al, 2011; Wolf, 2016).

From an animal model-to-human translational perspective, a limitation of rodent incubation of drug-craving studies is that the abstinence period preceding the relapse episodes

* Correspondence: Dr Y Shaham or Dr D Caprioli, Behavioral Neuroscience Branch, IRP, NIDA, 25I Bayview Boulevard, Suite 200, Baltimore, MD 21044, USA, Tel: 443740 2723, Fax: 4437402727 , E-mail: yavin.shaham@nih.gov or daniele.caprioli@uniromal.it

Received 26 September 2016 ; revised 12 December 20 I6; accepted 13 December 2016; accepted article preview online 27 December 2016 (operationally defined as the resumption of non-reinforced drug seeking during a period of abstinence) is experimenterimposed or forced and achieved by removing the subjects from the drug self-administration environment ( $\mathrm{Lu}$ et al, 2004; Venniro et al, 2016; Wolf, 2016). In contrast, abstinence in humans is often voluntary due to either the negative consequences of chronic drug use or the availability of competing alternative non-drug rewards (Epstein et al, 2006; Katz and Higgins, 2003); in the latter case, relapse vulnerability is high after loss of the alternative rewards (Heilig et al, 2016).

Based on the above-mentioned 'translational' considerations, we recently developed a rat model of incubation of methamphetamine craving after prolonged alternative reward choice-based voluntary abstinence (Caprioli et al, 2015a; Caprioli et al, 2016). Our model is based on studies showing that most rats strongly prefer the non-drug reward when given a mutually exclusive choice between cocaine or methamphetamine and palatable food (Cantin et al, 2010; Caprioli et al, 2015b; Lenoir et al, 2007). In our first study (Caprioli et al, 2015a), we trained food-sated male SpragueDawley rats to self-administer palatable food (6 sessions) and then to self-administer methamphetamine under two conditions: 12 sessions ( $9 \mathrm{~h} /$ day) or 50 sessions ( $3 \mathrm{~h} /$ day); we chose these training conditions based on the escalation or DSM-IV rodent addiction models (Ahmed and Koob, 1998; DerocheGamonet et al, 2004). We then assessed methamphetamine seeking in relapse tests after 1 or 21 abstinence days; during 
testing, lever presses led to contingent delivery of a light cue previously paired with methamphetamine infusions but not methamphetamine (extinction conditions). Between tests, the rats underwent voluntary abstinence for 19 days (achieved via a mutually exclusive discrete choice procedure between methamphetamine and the palatable food in which, on any given trial, the rats can earn the food or drug reward but not both; 20 trials/day). Under our voluntary abstinence procedure, most rats achieve complete methamphetamine abstinence during most of the choice sessions (ie, zero choices of methamphetamine infusions), whereas some rats continue to occasionally self-administer a small number of drug infusions during these sessions (Caprioli et al, 2015a; Caprioli et al, 2016; Caprioli et al, 2015b) (see Figure 2). We found that under both training conditions, methamphetamine seeking in the extinction tests was higher after 21 abstinence days than after 1 day, demonstrating incubation of drug craving after voluntary abstinence. We also found that 'incubated' drug seeking on voluntary abstinence day 21 was similar in magnitude to the incubated drug seeking observed on forced abstinence day 21 (Caprioli et al, 2015a).

The goal of our present study was to determine the generality of the phenomenon of incubation of drug craving after choice-based voluntary abstinence that we observed in male rats trained to self-administer methamphetamine. Many studies over the years have shown behavioral and mechanistic differences between opiate and psychostimulant drugs (Badiani et al, 2011; Ettenberg, 2009; Ettenberg et al, 1982; Mello and Negus, 1996). Therefore, we studied whether incubation of drug craving after voluntary abstinence generalizes to the opiate drug heroin. In addition, several studies have demonstrated sex differences in psychostimulant self-administration and relapse (Anker and Carroll, 2011; Carroll and Lynch, 2016; Carroll et al, 2004; Lynch et al, 2002), including incubation of cocaine craving after forced abstinence (Kerstetter et al, 2008) and cue-induced methamphetamine seeking (Cox et al, 2013). Therefore, we compared incubation of methamphetamine and heroin craving after voluntary (and forced) abstinence in male versus female rats.

\section{MATERIALS AND METHODS}

For subjects, drugs, intravenous surgery, apparatus, food pellets self-administration, drug self-administration, discretetrials choice procedure, abstinence phase, and relapse tests, see Supplementary Material online.

\section{Exp. 1: Incubation of Methamphetamine Craving in Males and Female Rats After Forced and Voluntary Abstinence}

The goal of Exp. 1 was to compare incubation of methamphetamine craving after forced and voluntary abstinence between male and female Sprague-Dawley rats. We used four groups of rats (Supplementary Figure S1) that we trained and tested at the same time (voluntary abstinence: $n=10$ males and 11 females; forced abstinence: $n=10$ males and 10 females) in a mixed experimental design that included the between-subjects factors of Abstinence Condition (forced, voluntary) and Sex (male, female), and the within-subjects factor of Abstinence Day (1, 21). This experiment consisted of three experimental conditions: training phase, discrete choice test, and relapse tests.

Training. We first trained rats to self-administer palatable food pellets ( 6 sessions, $6 \mathrm{~h} /$ session; 5 pellets per reward delivery) and then trained them to self-administer methamphetamine (12 sessions, $6 \mathrm{~h} / \mathrm{session} ; 0.1 \mathrm{mg} / \mathrm{kg} /$ infusion per drug delivery).

Discrete choice tests. We determined food versus methamphetamine preference using mutually exclusive discrete choice after every three-consecutive drug selfadministration sessions in all four groups (three-choice tests) and for 19 days in the voluntary abstinence groups.

Relapse tests. We tested the forced and voluntary abstinence male and female rats for methamphetamine seeking under extinction conditions on abstinence days 1 and 21 . The duration of the test session was $30 \mathrm{~min}$ on day 1 and $2 \mathrm{~h}$ on day 21. The duration of the test session on day 1 was $30 \mathrm{~min}$ to minimize carryover effect of extinction learning, which may subsequently decrease drug seeking on day 21 testing.

\section{Exp. 2: Incubation of Heroin Craving in Males and Female Rats After Forced and Voluntary Abstinence}

The goal of this experiment was to determine whether incubation of drug craving after voluntary abstinence generalizes to the opiate drug heroin. We used four groups of rats (Supplementary Figure S1) that we trained and tested at the same time (voluntary abstinence: $n=15$ males and 16 females; forced abstinence: $n=11$ males and 15 females) in a mixed experimental design that included the betweensubjects factors of Abstinence Condition (forced, voluntary) and Sex (male, female), and the within-subjects factor of Abstinence Day $(1,21)$. This experiment consisted of three experimental conditions training phase, discrete choice test, and the relapse test.

Training. We first trained rats to self-administer palatable food pellets ( 6 sessions, $6 \mathrm{~h} /$ session; 5 pellets per reward delivery) and then trained them to self-administer heroin (12 sessions, $6 \mathrm{~h} / \mathrm{session} ; 0.1 \mathrm{mg} / \mathrm{kg} /$ infusion per drug delivery).

Discrete choice tests. We determined food versus heroin using a mutually exclusive discrete choice procedure after every three-consecutive drug self-administration sessions in all four groups (three-choice tests) and for 19 days in the voluntary abstinence groups.

Relapse test. We tested forced and voluntary abstinence male and female rats for heroin seeking under extinction conditions on abstinence days 1 and 21. As in Exp. 1, the duration of the test session was $30 \mathrm{~min}$ on day 1 and $2 \mathrm{~h}$ on day 21 . 


\section{Statistical Analyses}

We analyzed the data with the statistical program SPSS using GLM module. We analyzed all methamphetamine and heroin data separately. For the training phase, we analyzed the data separately for food rewards and drug infusions with mixed ANOVA, using the within-subjects factor of Session and the between-subjects factor of Sex (male, female). Because of the differences in body weight between male and female rats, we converted the number of rewards for palatable food pellets using the following formula: (number of reward $\times$ gram of one palatable food pellet $\times 5$ )/1000)/ (body weight/1000). For the choice tests, we analyzed the data with mixed ANOVA, using the between-subjects factor of Sex and the within-subjects factors of Choice session and Reward type (food, drug). For the relapse tests, we analyzed inactive and active lever presses during the sessions using mixed ANOVA with the between-subjects factors of Abstinence condition (forced, voluntary) and Sex (male, female), and the within-subjects factors of Abstinence day (1, 21) and Lever (inactive, active). As our multifactorial ANOVAs yielded multiple main and interaction effects, we only report significant effects that are critical for data interpretation (see Supplementary Table S1 for a complete reporting of the statistical analyses).

\section{RESULTS}

\section{Exp. 1: Incubation of Methamphetamine Craving in Males and Female Rats After Forced and Voluntary Abstinence}

Training. During training for food self-administration, female rats earned significantly more food rewards relative to their body weight than male rats, but this difference decreased over time (Figure 1b). We observed a significant main effect of Sex $\left(\mathrm{F}_{1,39}=17.5, p<0.0001\right)$ and an interaction between Session and Sex $\left(\mathrm{F}_{5,195}=3.1, p=0.01\right)$. During training for methamphetamine self-administration, the male and female rats escalated their methamphetamine intake over time with somewhat steeper escalation in males (Figure 1c). We observed a significant effect of Session $\left(\mathrm{F}_{11,429}=69.0, p<0.0001\right)$ and an interaction between Session and Sex $\left(\mathrm{F}_{11,429}=2.2, p=0.01\right)$. During the three discrete choice sessions, the male and female rats showed a strong preference for food, an effect that was somewhat stronger in males (Figure 1d). We observed a significant main effect of Reward type $\left(\mathrm{F}_{1,39}=226.8, p<0.0001\right)$, Sex $\left(\mathrm{F}_{1,39}=5.1, p=0.03\right)$, and an interaction between Reward type and Session $\left(\mathrm{F}_{2,78}=7.4, p=0.001\right)$.

Abstinence phase. During the 3-week abstinence phase, the male and female rats in the voluntary abstinence groups showed a strong preference for food, but this preference was somewhat lower for females (Figure 2a). We observed a significant effect of Reward type $\left(\mathrm{F}_{1,19}=854.1, p<0.0001\right)$ and an interaction between Reward type and Sex $\left(\mathrm{F}_{1,19}=7.4\right.$, $p=0.01)$.

Relapse tests. Active lever presses during the tests were higher after 21 abstinence days than after 1day (Figure 3a), demonstrating incubation of methamphetamine craving after forced or voluntary abstinence in male and female rats. We observed a significant interaction between Abstinence day and Lever $\left(F_{1,37}=72.6, p<0.0001\right)$, but no effects of Abstinence condition or Sex, or any interactions between these factors. In addition, analysis of the time course data of active lever presses of the entire $2 \mathrm{~h}$ session on day 21 showed a significant main effect of Session hour $\left(\mathrm{F}_{1,37}=120.4\right.$, $p<0.0001$ ), but no effects of Abstinence condition or Sex, or interactions between the factors. Finally, inactive lever presses were very low (mean responding of $1.0 \pm 0.4$ to $5.4 \pm 2.0$ in the different conditions) and did not differ between the abstinence days, the abstinence conditions, or the sexes $(p$-values $>0.05)$.

\section{Exp. 2: Incubation of Heroin Craving in Males and Female Rats After Forced and Voluntary Abstinence}

Training. As in Exp. 1, during food self-administration training, female rats earned significant more food rewards relative to their body weight than male rats, and this difference decreased over time (Figure 1e). We observed a significant effect of Sex $\left(\mathrm{F}_{1,55}=10.8, p=0.002\right)$ and an interaction between Session and Sex $\left(\mathrm{F}_{2,275}=5.1, p<0.0001\right)$. During training for heroin self-administration, both male and female rats increased their drug intake over time (Figure 1f). We observed a significant effect of Session $\left(\mathrm{F}_{11,605}=15.0, p<0.0001\right)$ but no effects of Sex or an interaction between the two factors ( $p$-values $>0.1$ ). During the three discrete choice sessions, both male and female rats showed a strong preference for food (Figure 1g). We observed a significant effect of Reward type $\left(\mathrm{F}_{1,55}=1002.2\right.$, $p<0.0001)$ and an interaction between Reward type and Session $\left(\mathrm{F}_{2,110}=48.8, p<0.0001\right)$, but no significant effect of Sex or interactions between Sex and the other factors $(p$-values $>0.1)$.

Abstinence phase. During the 3-week abstinence phase, male and female rats in the voluntary abstinence groups showed a strong preference for food (Figure 2c). We observed a significant effect of Reward type $\left(\mathrm{F}_{1,29}=15606.5, p<0.0001\right)$ and an interaction between Reward type and Session $\left(\mathrm{F}_{18,522}=1.8, p=0.019\right)$.

Relapse tests. Active lever presses during the tests were higher after 21 abstinence days than after 1 day in the forced but not voluntary abstinence condition (Figure 3d), demonstrating incubation of heroin craving after forced but not voluntary abstinence in male and female rats. The statistical analysis included the between-subjects factors of Sex and Abstinence condition (forced, voluntary), and the withinsubjects factors of Abstinence day $(1,21)$ and Lever (active, inactive). We observed a significant interaction between Abstinence day and Abstinence condition $\left(\mathrm{F}_{1,53}=10.8\right.$, $p=0.002$ ). In addition, analysis of the time course data of active lever presses of the entire $2 \mathrm{~h}$ session on day 21 showed significant main effects of Abstinence condition $\left(\mathrm{F}_{1,53}=11.7\right.$, $p=0.001)$ and Session hour $\left(\mathrm{F}_{1,53}=73.0, p<0.0001\right)$. Finally, inactive lever presses were very low (mean responding of $1.3 \pm 0.3$ to $5.8 \pm 1.1$ in the different conditions) and did not differ between the abstinence days, the abstinence conditions, or the sexes ( $p$-values $>0.05)$. 


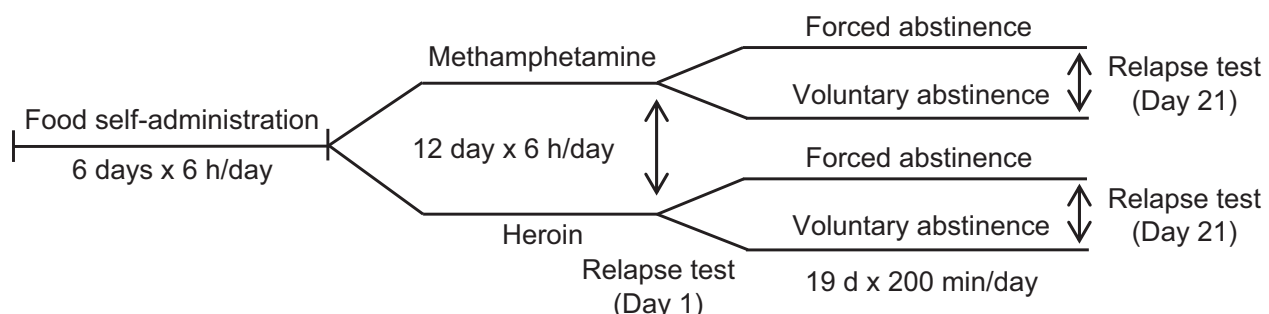

Methamphetamine
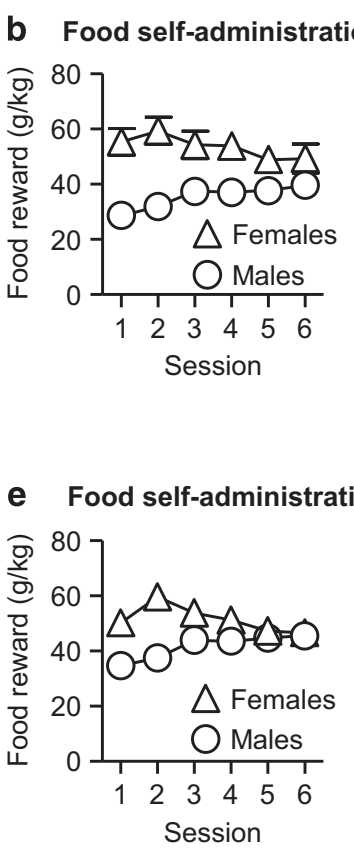

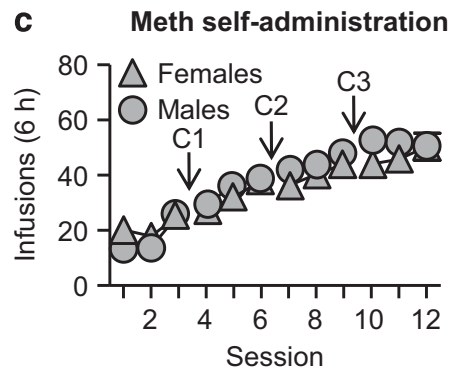

Heroin

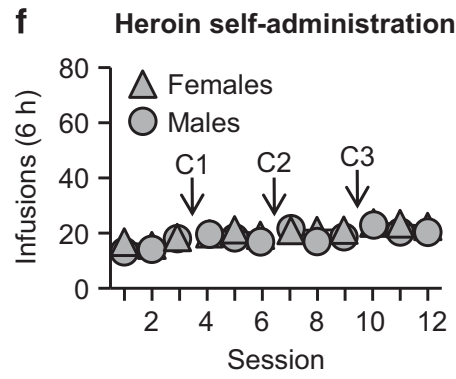

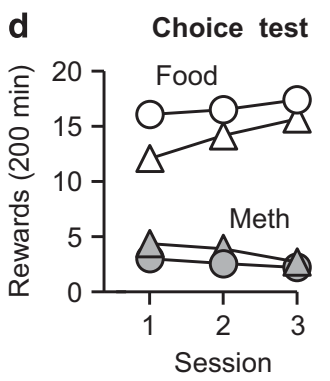

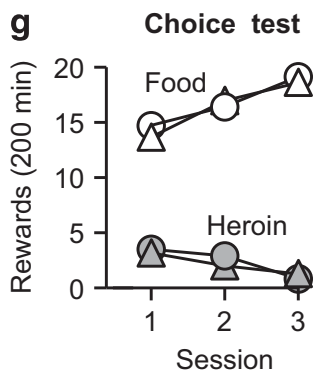

Figure I Experimental timeline and self-administration training for palatable food, methamphetamine, and heroin in male and female rats. (a) Timeline of the experiment. (b) Food self-administration for methamphetamine-trained rats: mean \pm SEM amount of food rewards in $\mathrm{g} / \mathrm{kg}$ during the $6 \mathrm{~h}$ sessions. (c) Methamphetamine self-administration: mean \pm SEM number of methamphetamine infusions during the $6 \mathrm{~h}$ sessions. C, choice sessions. (d) Discrete choice tests: mean \pm SEM food rewards and methamphetamine infusions earned during the three discrete choice sessions during training. (e) Food self-administration for heroin-trained rats: mean \pm SEM amount of food rewards in $\mathrm{g} / \mathrm{kg}$ during the $6 \mathrm{~h}$ sessions. ( $\mathrm{f}$ ) Heroin self-administration: mean $\pm \mathrm{SEM}$ number of heroin infusions during the $6 \mathrm{~h}$ sessions. C, choice sessions. (g) Discrete choice tests: mean \pm SEM food rewards and heroin infusions earned during the three discrete choice sessions during training. Methamphetamine: females, $n=21$, males, $n=20$; Heroin: females, $n=31$, males, $n=26$.

\section{DISCUSSION}

We recently introduced an animal model of incubation of methamphetamine craving after choice-based voluntary abstinence in male rats (Caprioli et al, 2015a). In the present study, we determined the generality of this phenomenon to female rats and to male and female rats with a history of heroin self-administration. There are two main findings in our study. The first is that we found no sex differences in incubation of methamphetamine craving after voluntary abstinence. The second is that choice-based voluntary abstinence prevented the emergence of incubation of heroin craving in both sexes. We also found no evidence for sex differences in methamphetamine or heroin self-administration, the strong preference for the palatable food over these drugs, and incubation of drug craving after forced abstinence. Finally, we found that after adjusting for body weight, female rats self-administered more palatable food than male rats, an observation in agreement with some studies (Klump et al, 2013; Reichelt et al, 2016) but not others (Cifani et al, 2012; Pickens et al, 2012).

\section{Incubation of Methamphetamine Craving After Voluntary or Forced Abstinence In Male and Female Rats}

In Exp. 1 we found no evidence for sex differences in methamphetamine self-administration and incubation of drug craving after voluntary or forced abstinence. This pattern of results contrasts with previous reports on sex differences in methamphetamine self-administration and relapse, showing that compared with male rats, female rats acquire methamphetamine self-administration faster, and show potentiated cue- and drug priming-induced reinstatement of methamphetamine seeking after extinction (Cox et al, 2013; Holtz et al, 2012; Reichel et al, 2012; Roth 
Methamphetamine
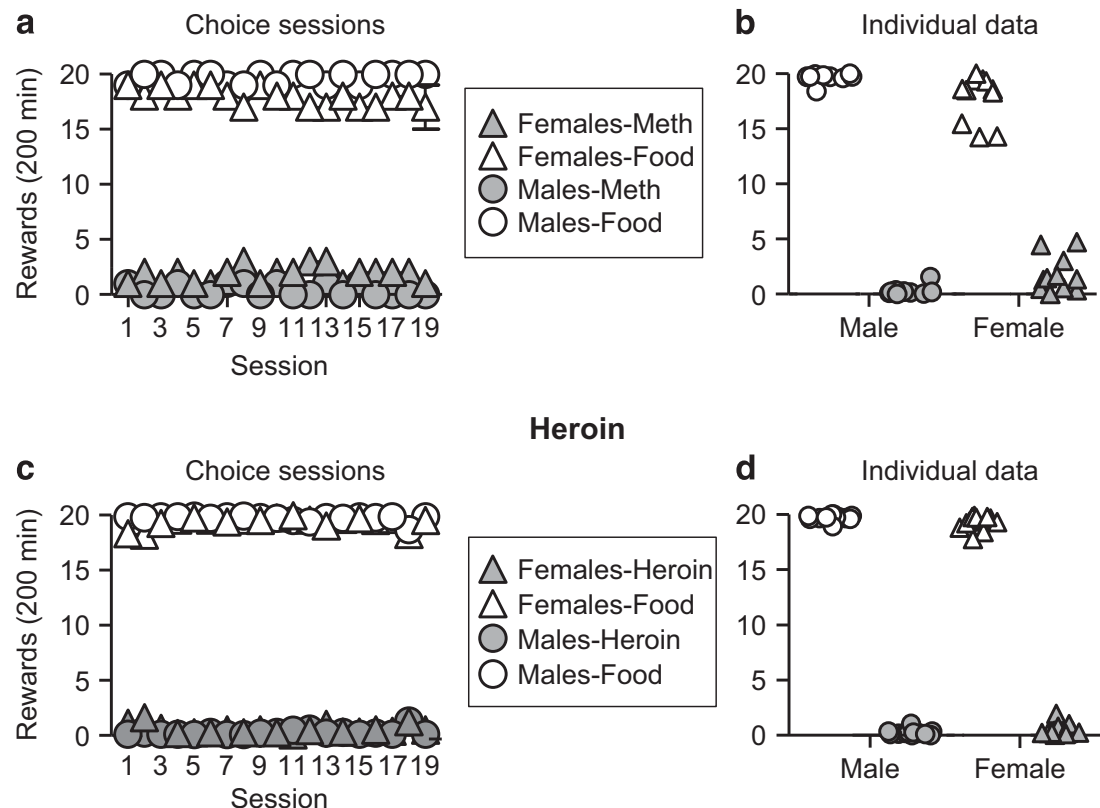

Heroin
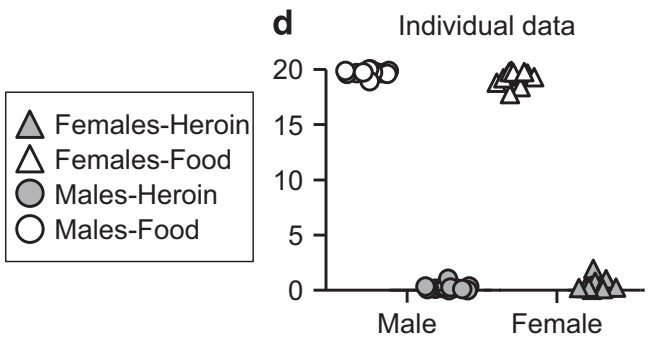

Figure 2 Voluntary abstinence. (a) Methamphetamine voluntary abstinence: mean \pm SEM food rewards (5 pellets per reward delivery) and methamphetamine infusions earned during the 19 discrete choice sessions. (b) Individual data for methamphetamine voluntary abstinence: individual mean food rewards and methamphetamine infusions earned across the 19 discrete choice sessions. (c) Heroin voluntary abstinence: mean \pm SEM food rewards (5 pellets per reward delivery) and heroin infusions earned during the 19 discrete choice sessions. (d) Individual data for heroin voluntary abstinence: individual mean food rewards and heroin infusions earned across the 19 discrete choice sessions. Methamphetamine: females, $n=1 \mathrm{I}, \mathrm{males,} n=10$; Heroin: females, $n=16$, males, $n=15$.

and Carroll, 2004). What might account for our results showing no sex differences in methamphetamine selfadministration and relapse and the reported sex differences in the above-mentioned studies?

Regarding methamphetamine self-administration, we suspect that the negative results in our study versus the positive results of sex differences in the previous studies (Reichel et al, 2012; Roth and Carroll, 2004) are due to the use of higher unit dose in our study than in these studies. Indeed, there is evidence that sex differences in cocaine and nicotine self-administration are more apparent when low drug doses are used (Carroll et al, 2001; Donny et al, 2000; Lynch and Carroll, 1999). Regarding the methamphetamine unit dose in our study, we chose a high dose $(0.1 \mathrm{mg} / \mathrm{kg})$ based on our previous reports in male rats showing reliable selfadministration and incubation of drug craving after forced abstinence with this dose (Caprioli et al, 2015a; Li et al, 2015; Shepard et al, 2004; Theberge et al, 2013).

Regarding relapse, our findings of the lack of sex differences in relapse to methamphetamine seeking are different from those reported using the classical reinstatement model (Shaham et al, 2003) of higher cue- and drug priming-induced reinstatement in female rats than in male rats (Cox et al, 2013; Reichel et al, 2012). In reconciling the differences between our results and those of these previous studies, an important consideration is that there is evidence that the mechanisms underlying reinstatement after extinction in the self-administration environment can be dissociable from those controlling drugs seeking during forced abstinence in the homecage without extinction training (Fuchs et al, 2006; Marchant et al, 2013). We speculate that extinction training, which causes neuroadaptations in brain areas critical for reinstatement of drug seeking like the nucleus accumbens (Knackstedt et al, 2010; Self et al, 2004), may recruit sex-specific mechanisms that increase the sensitivity of female rats to methamphetamine priming- and cue-induced reinstatement of drug seeking. Thus, sex differences in reinstatement of drug seeking after extinction may not generalize to abstinence-based models of drug relapse in which extinction procedures are not used.

Another finding in Exp. 1 was the lack of sex differences in the strong preference for palatable food over methamphetamine. There are no published studies on sex differences between methamphetamine and palatable food. However, our results are different from results reported in two studies showing that a higher proportion of female rats prefer cocaine over food (Kerstetter et al, 2012; Perry et al, 2013). Comparison across choice studies using different drugs and different food types should be done with caution. However, we suspect that the strong preference for food and lack of sex differences in our study are due to the use of a high reward magnitude (five pellets per reward delivery) and a highly palatable food that is preferred over all other commercially available $45 \mathrm{mg}$ pellet types of different food compositions and flavors (Calu et al, 2014), which is more resistant to punishment-induced suppression of operant responding than methamphetamine (Krasnova et al, 2014). In contrast, in the above-mentioned cocaine choice studies, investigators have used pellet types that were less preferred than our pellet type and lever presses led to the delivery of a single food pellet, allowing for the detection of both individual 
Methamphetamine

a

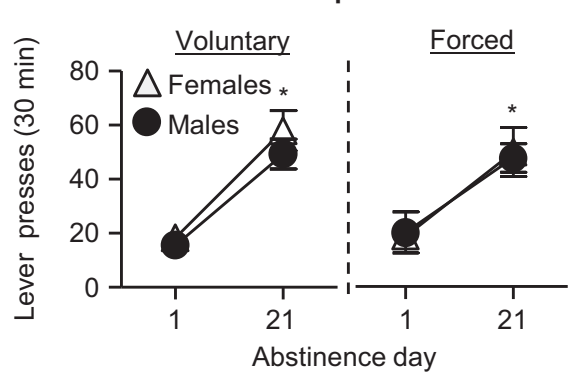

b
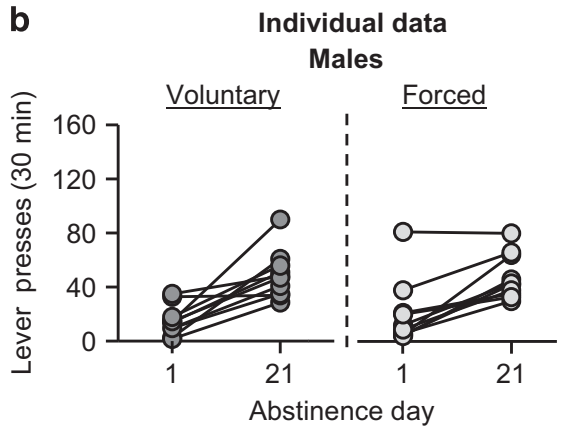

Females
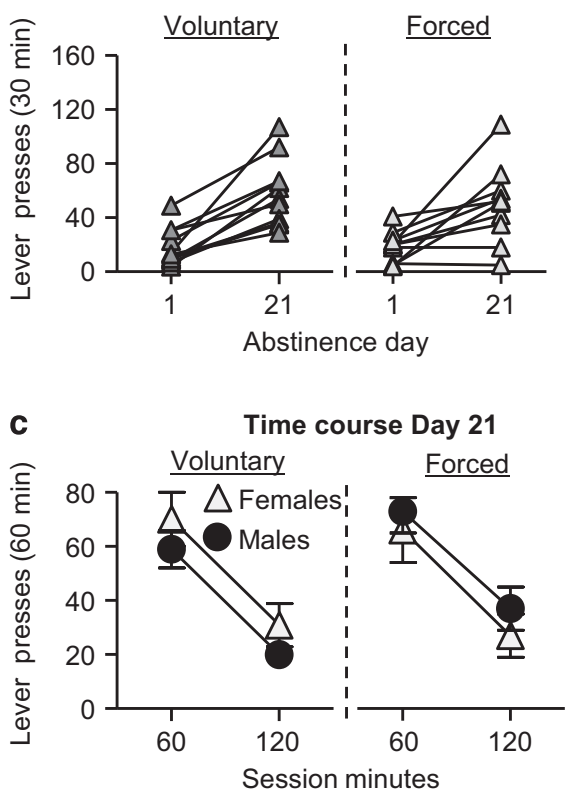

\section{Heroin}
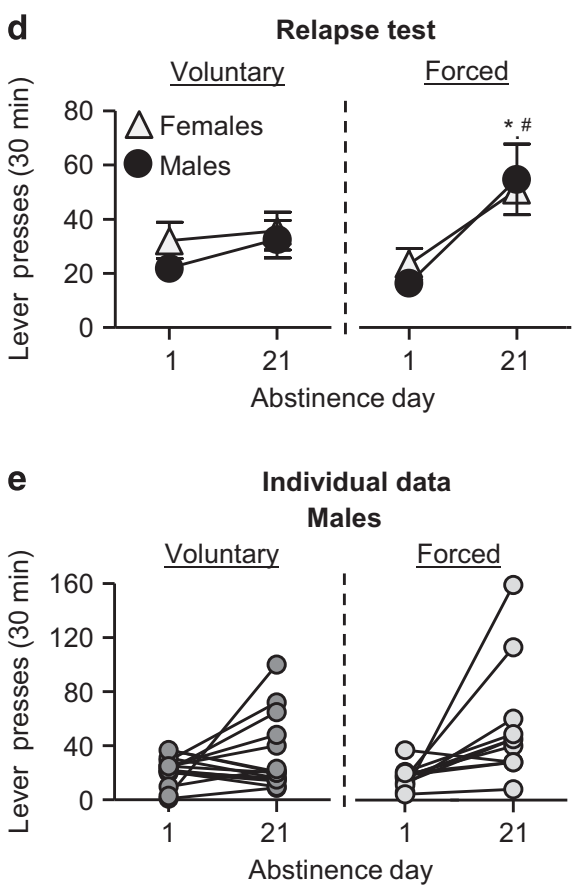

Females
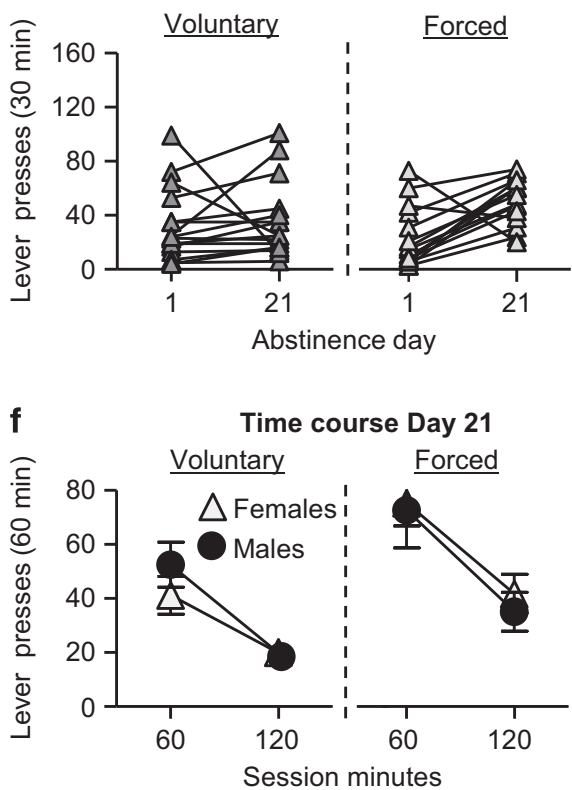

Figure 3 Relapse tests (a) Methamphetamine seeking on abstinence days I and 2 I (group data): mean \pm SEM lever presses during the 30 min relapse tests. (b) Methamphetamine: individual data: individual lever presses during the tests. (c) Methamphetamine seeking on day 21 (time course, group data): mean \pm SEM lever presses at each hour of the test session on day 2 I. (d) Heroin seeking on abstinence on days I and 21 (group data): mean \pm SEM lever presses during the $30 \mathrm{~min}$ relapse tests. (e) Heroin: individual data: individual lever presses during the tests. (f) Heroin seeking on day 21 (time course, group data): mean \pm SEM lever presses at each hour of the test session on day 21 . * Different from day I, $p<0.05$; ${ }^{\#}$ Different from voluntary abstinence day 21 , $p<0.05$. Methamphetamine: voluntary abstinence: $n=10$ males and II females; forced abstinence: $n=10$ males and 10 females. Heroin: voluntary abstinence: $n=15$ males and 16 females; forced abstinence: $n=1 \mid$ males and 15 females.

differences and sex differences in cocaine versus food choice (Kerstetter et al, 2012; Perry et al, 2013).

Finally, the lack of sex differences in incubation of methamphetamine craving after forced abstinence were not predicted based on a comprehensive study of Kerstetter et al (2008) showing sex differences in incubation of cocaine craving. An important consideration regarding these discrepant results is that recent evidence indicates mechanistic differences in incubation of cocaine versus methamphetamine craving (Li et al, 2015; Scheyer et al, 2016). Thus, sex differences in brain function that impact mechanisms of 
incubation of cocaine craving may not generalize to incubation of methamphetamine craving.

\section{Incubation of Heroin Craving After Forced But Not Voluntary Abstinence in Males and Females}

In Exp. 2, we observed robust incubation of heroin craving after forced but not voluntary abstinence in both sexes. These results show an unexpected dissociation between methamphetamine and heroin for incubation of drug craving after voluntary abstinence.

We propose that this dissociation should be considered within the context of a large body of studies, suggesting that opiate reward and relapse, as assessed in rodent and monkey models, are mediated at least in part by behavioral and neurobiological mechanisms that are distinct from those of psychostimulants (Badiani et al, 2011; Ettenberg, 2009). Particularly relevant here is the demonstration that opioid receptors are critical for heroin but not psychostimulant reward (Badiani et al, 2011; Ettenberg et al, 1982; Mello and Negus, 1996). Endogenous opioid systems and opioid receptors have a critical role in palatable food reward (Baldo, 2016; Gosnell and Levine, 2009; Kelley and Berridge, 2002; Levine et al, 1985; Mena et al, 2013; Pecina and Berridge, 2005). Thus, we speculate that in our mutually exclusive choice-based voluntary abstinence procedure, the palatable food pellets act as a substitute for heroin (but not methamphetamine) in a manner akin to agonist substitution therapy (Dole, 1988; Dole and Nyswander, 1965), leading to decreased heroin seeking 1 day after the removal of the food substitute.

An alternative explanation of our data is that inhibition of incubation of heroin craving was due to some heroin exposure during voluntary abstinence (mean of 0.1 and 0.5 infusions per day or 0.01 and $0.05 \mathrm{mg} / \mathrm{kg} /$ day for males and females, respectively). Although we cannot rule out this possibility, we believe it is unlikely, because we found no correlation between drug intake during the choice sessions and active lever presses on the relapse test on day 21 (Pearson $r=0.09$ ).

Two other findings in Exp. 2 were the lack of sex differences in heroin self-administration or the strong preference for the palatable food over heroin during the choice-based voluntary abstinence phase. The lack of sex differences in heroin selfadministration in our study agrees with those from an early study, demonstrating similar heroin self-administration in males and females over a range of unit doses (0.06125 to $0.05 \mathrm{mg} / \mathrm{kg} /$ infusion) (Stewart et al, 1996). However, our results and those of Stewart et al (1996) are different from those of two other studies, showing that female rats acquired morphine and heroin self-administration faster than males (Cicero et al, 2003; Lynch and Carroll, 1999). A tentative conclusion from our study and these previous studies is that it has not been established that sex differences have a major role in heroin reward and relapse in rat models.

Finally, another finding in our study is the lack of sex differences in the strong preference for palatable food over heroin. At present, there are no published studies on sex differences in choice between heroin and food in animal models. However, our findings are consistent with previous reports of strong preference for a saccharin solution over heroin in male rats (Lenoir et al, 2013; Madsen and Ahmed, 2015; Vandaele et al, 2016).

\section{Clinical Implications and Future Research Directions}

In human addicts, abstinence is often voluntary due to the availability of alternative non-drug rewards (Epstein and Preston, 2003; Marlatt, 1996). This is exemplified in contingency management treatment where non-drug rewards (eg, monetary vouchers) given in exchange for being drug free (verified by drug testing) maintains prolonged abstinence (Higgins et al, 2004; Preston et al, 2002; Stitzer and Petry, 2006). However, when contingency management is discontinued, most addicts relapse to drug use (Roll, 2007; Silverman et al, 2012). As argued elsewhere, our rat model of relapse/incubation after choice-based voluntary abstinence is analogous to the human condition of relapse to drug use after termination of contingency management (Caprioli et al, 2015a). Regarding the 'translational' value of our new model, the data on lack of sex differences in both the efficacy of our choice-based procedure in inhibiting drug selfadministration and relapse after cessation of 'contingency management' agree with the lack of gender differences in the efficacy of contingency management or the high relapse rates after treatment cessation in humans (Epstein et al, 2009; Lussier et al, 2006; Roll et al, 2013).

Our results have implications for future studies on incubation of methamphetamine and heroin craving, considering the recent NIH mandate of including both males and females in preclinical biomedical studies. Specifically, we found no evidence for sex differences in incubation of methamphetamine or heroin craving. Therefore, we tentatively suggest that in studies on incubation of drug craving it may not be necessary to use sex as an independent variable and double the $n$ per experimental condition. Instead, we suggest including both males and females (preferably equal number) in each experimental condition, as advocated by Joel and McCarthy (2016) for behavioral models in which sex differences are not observed. This suggestion also makes sense, as we have observed similar variability in the behavioral response of the male and female rats under the different experimental conditions (see Figures 1,2,3), confirming recent meta-analyses of rodent studies indicating similar variability in males and females in different behavioral tasks (Becker et al, 2016; Prendergast et al, 2014).

Finally, although our new animal model mimics some features of human choice-based abstinence, it does not incorporate an important aspect of human drug addiction: the social environment (Heilig et al, 2016). In our study and most previous incubation of drug-craving studies (Venniro et al, 2016), the male and female rats were socially isolated. Thus, a question for future research is whether socially housing the rats, which previously shown to decrease incubation of cocaine craving after forced abstinence in male rats (Chauvet et al, 2012; Thiel et al, 2012), will also decrease incubation of drug craving after voluntary abstinence.

\section{FUNDING AND DISCLOSURE}

This research was supported by the Intramural Research Program of NIDA and NARSAD (Brain \& Behavior Research Foundation) Distinguished Investigator Grant (YS). The authors declare no conflict of interest. 


\section{REFERENCES}

Abdolahi A, Acosta G, Breslin FJ, Hemby SE, Lynch WJ (2010). Incubation of nicotine seeking is associated with enhanced protein kinase A-regulated signaling of dopamine- and cAMPregulated phosphoprotein of $32 \mathrm{kDa}$ in the insular cortex. Eur J Neurosci 31: 733-741.

Ahmed SH, Koob GF (1998). Transition from moderate to excessive drug intake: change in hedonic set point. Science 282: 298-300.

Anker JJ, Carroll ME (2011). Females are more vulnerable to drug abuse than males: evidence from preclinical studies and the role of ovarian hormones. Curr Top Behav Neurosci 8: 73-96.

Badiani A, Belin D, Epstein D, Calu D, Shaham Y (2011). Opiate versus psychostimulant addiction: the differences do matter. Nat Rev Neurosci 12: 685-700.

Baldo BA (2016). Prefrontal cortical opioids and dysregulated motivation: a network hypothesis. Trends Neurosci 39: 366-377.

Becker JB, Prendergast BJ, Liang JW (2016). Female rats are not more variable than male rats: a meta-analysis of neuroscience studies. Biol Sex Differ 7: 34.

Bienkowski P, Rogowski A, Korkosz A, Mierzejewski P, Radwanska $\mathrm{K}$, Kaczmarek L et al (2004). Time-dependent changes in alcoholseeking behaviour during abstinence. Eur Neuropsychopharmacol 14: $355-360$.

Calu DJ, Chen YW, Kawa AB, Nair SG, Shaham Y (2014). The use of the reinstatement model to study relapse to palatable food seeking during dieting. Neuropharmacology 76 Pt B: 395-406.

Cantin L, Lenoir M, Augier E, Vanhille N, Dubreucq S, Serre F et al (2010). Cocaine is low on the value ladder of rats: possible evidence for resilience to addiction. PLOS ONE 5: e11592.

Caprioli D, Venniro M, Zeric T, Li X, Adhikary S, Madangopal R et al (2015a). Effect of the novel positive allosteric modulator of metabotropic glutamate receptor 2 AZD8529 on incubation of methamphetamine craving after prolonged voluntary abstinence in a rat model. Biol Psychiatry 78: 463-473.

Caprioli D, Venniro M, Zhang M, Bossert JM, Warren BL, Hope BT et al (2016). Role of dorsomedial striatum neuronal ensembles in incubation of methamphetamine craving after voluntary abstinence. J Neurosci (in press).

Caprioli D, Zeric T, Thorndike EB, Venniro M (2015b). Persistent palatable food preference in rats with a history of limited and extended access to methamphetamine self-administration. Addict Biol 20: 913-926.

Carroll ME, Campbell UC, Heideman P (2001). Ketoconazole suppresses food restriction-induced increases in heroin selfadministration in rats: sex differences. Exp Clin Psychopharmacol 9: 307-316.

Carroll ME, Lynch WJ (2016). How to study sex differences in addiction using animal models. Addict Biol.

Carroll ME, Lynch WJ, Roth ME, Morgan AD, Cosgrove KP (2004). Sex and estrogen influence drug abuse. Trends Pharmacol Sci 25: 273-279.

Chauvet C, Goldberg SR, Jaber M, Solinas M (2012). Effects of environmental enrichment on the incubation of cocaine craving. Neuropharmacology 63: 635-641.

Cicero TJ, Aylward SC, Meyer ER (2003). Gender differences in the intravenous self-administration of mu opiate agonists. Pharmacol Biochem Behav 74: 541-549.

Cifani C, Koya E, Navarre BM, Calu DJ, Baumann MH, Marchant NJ et al (2012). Medial prefrontal cortex neuronal activation and synaptic alterations after stress-induced reinstatement of palatable food seeking: a study using c-fos-GFP transgenic female rats. J Neurosci 32: 8480-8490.

Cox BM, Young AB, See RE, Reichel CM (2013). Sex differences in methamphetamine seeking in rats: impact of oxytocin. Psychoneuroendocrinology 38: 2343-2353.
Deroche-Gamonet V, Belin D, Piazza PV (2004). Evidence for addiction-like behavior in the rat. Science 305: 1014-1017.

Dole VP (1988). Implications of methadone maintenance for theories of narcotic addiction. J Am Med Assoc 260: 3025-3029.

Dole VP, Nyswander M (1965). A medical treatment for diacetylmorphine (heroin) addiction. a clinical trial with methadone hydrochloride. JAMA 193: 646-650.

Donny EC, Caggiula AR, Rowell PP, Gharib MA, Maldovan V, Booth $S$ et al (2000). Nicotine self-administration in rats: estrous cycle effects, sex differences and nicotinic receptor binding. Psychopharmacology (Berl) 151: 392-405.

Epstein DH, Preston KL (2003). The reinstatement model and relapse prevention: a clinical perspective. Psychopharmacology 168: $31-41$.

Epstein DH, Preston KL, Stewart J, Shaham Y (2006). Toward a model of drug relapse: an assessment of the validity of the reinstatement procedure. Psychopharmacology (Berl) 189: 1-16.

Epstein DH, Schmittner J, Umbricht A, Schroeder JR, Moolchan ET, Preston KL (2009). Promoting abstinence from cocaine and heroin with a methadone dose increase and a novel contingency. Drug Alcohol Depend 101: 92-100.

Ettenberg A (2009). The runway model of drug self-administration. Pharmacol Biochem Behav 91: 271-277.

Ettenberg A, Pettit HO, Bloom FE, Koob GF (1982). Heroin and cocaine intravenous self-administration in rats: mediation by separate neural systems. Psychopharmacology (Berl) 78: 204-209.

Fanous S, Goldart EM, Theberge FR, Bossert JM, Shaham Y, Hope BT (2012). Role of orbitofrontal cortex neuronal ensembles in the expression of incubation of heroin craving. J Neurosci 32: 11600-11609.

Fuchs RA, Branham RK, See RE (2006). Different neural substrates mediate cocaine seeking after abstinence versus extinction training: a critical role for the dorsolateral caudate-putamen. J Neurosci 26: 3584-3588.

Funk D, Coen K, Tamadon S, Hope BT, Shaham Y, Lê AD (2016). Role of central amygdala neuronal ensembles in incubation of nicotine craving. J Neurosci 36: 8612-8623.

Gawin FH, Kleber HD (1986). Abstinence symptomatology and psychiatric diagnosis in cocaine abusers. Clinical observations. Arch Gen Psychiatry 43: 107-113.

Gosnell BA, Levine AS (2009). Reward systems and food intake: role of opioids. Int J Obes (Lond) 33: S54-S58.

Grimm JW, Hope BT, Wise RA, Shaham Y (2001). Incubation of cocaine craving after withdrawal. Nature 412: 141-142.

Heilig M, Epstein DH, Nader MA, Shaham Y (2016). Time to connect: bringing social context into addiction neuroscience. Nat Rev Neurosci 17: 592-599.

Higgins ST, Heil SH, Lussier JP (2004). Clinical implications of reinforcement as a determinant of substance use disorders. Annual Rev Psychol 55: 431-461.

Holtz NA, Lozama A, Prisinzano TE, Carroll ME (2012). Reinstatement of methamphetamine seeking in male and female rats treated with modafinil and allopregnanolone. Drug Alcohol Dependence 120: 233-237.

Hunt WA, Barnett LW, Branch LG (1971). Relapse rates in addiction programs. J Clin Psychol 27: 455-456.

Joel D, McCarthy MM (2016). Incorporating sex as a biological variable in neuropsychiatric research: where are we now and where should we be? Neuropsychopharmacology 42: 379-385.

Katz JL, Higgins ST (2003). The validity of the reinstatement model of craving and relapse to drug use. Psychopharmacology (Berl) 168: $21-30$.

Kelley AE, Berridge KC (2002). The neuroscience of natural rewards: relevance to addictive drugs. J Neurosci 22: 3306-3311. 
Kerstetter KA, Aguilar VR, Parrish AB, Kippin TE (2008). Protracted time-dependent increases in cocaine-seeking behavior during cocaine withdrawal in female relative to male rats. Psychopharmacology (Berl) 198: 63-75.

Kerstetter KA, Ballis MA, Duffin-Lutgen S, Carr AE, Behrens AM, Kippin TE (2012). Sex differences in selecting between food and cocaine reinforcement are mediated by estrogen. Neuropsychopharmacology 37: 2605-2614.

Klump KL, Racine S, Hildebrandt B, Sisk CL (2013). Sex differences in binge eating patterns in male and female adult rats. Int $J$ Eat Disord 46: 729-736.

Knackstedt LA, Moussawi K, Lalumiere R, Schwendt M, Klugmann M, Kalivas PW (2010). Extinction training after cocaine selfadministration induces glutamatergic plasticity to inhibit cocaine seeking. J Neurosci 30: 7984-7992.

Krasnova IN, Marchant NJ, Ladenheim B, McCoy MT, Panlilio LV, Bossert JM et al (2014). Incubation of methamphetamine and palatable food craving after punishment-induced abstinence. Neuropsychopharmacology 39: 2008-2016.

Lenoir M, Cantin L, Vanhille N, Serre F, Ahmed SH (2013). Extended heroin access increases heroin choices over a potent nondrug alternative. Neuropsychopharmacology 38: 1209-1220.

Lenoir M, Serre F, Cantin L, Ahmed SH (2007). Intense sweetness surpasses cocaine reward. PLoS ONE 2: e698.

Levine AS, Morley JE, Gosnell BA, Billington CJ, Bartness TJ (1985). Opioids and consummatory behavior. Brain Res Bull 14: 663-672.

Li X, Zeric T, Kambhampati S, Bossert JM, Shaham Y (2015). The central amygdala nucleus is critical for incubation of methamphetamine craving. Neuropsychopharmacology 40: 1297-1306.

Lu L, Grimm JW, Hope BT, Shaham Y (2004). Incubation of cocaine craving after withdrawal: a review of preclinical data. Neuropharmacology 47: 214-226.

Lussier JP, Heil SH, Mongeon JA, Badger GJ, Higgins ST (2006). A meta-analysis of voucher-based reinforcement therapy for substance use disorders. Addiction 101: 192-203.

Lynch WJ, Carroll ME (1999). Sex differences in the acquisition of intravenously self-administered cocaine and heroin in rats. Psychopharmacology (Berl) 144: 77-82.

Lynch WJ, Roth ME, Carroll ME (2002). Biological basis of sex differences in drug abuse: preclinical and clinical studies. Psychopharmacology (Berl) 164: 121-137.

Madsen HB, Ahmed SH (2015). Drug versus sweet reward: greater attraction to and preference for sweet versus drug cues. Addict Biol 20: 433-444.

Marchant NJ, Li X, Shaham Y (2013). Recent developments in animal models of drug relapse. Curr Opin Neurobiol 23: 675-683.

Marlatt AG (1996). Models of relapse and relapse prevention: a commentary. Exp Clin Psychopharmacol 4: 55-60.

Mead AN, Zamanillo D, Becker N, Stephens DN (2007). AMPAreceptor GluR1 subunits are involved in the control over behavior by cocaine-paired cues. Neuropsychopharmacology 32: 343-353.

Mello NK, Negus SS (1996). Preclinical evaluation of pharmacotherapies for treatment of cocaine and opioid abuse using drug self-administration procedures. Neuropsychopharmacology 14: 375-424.

Mena JD, Selleck RA, Baldo BA (2013). Mu-opioid stimulation in rat prefrontal cortex engages hypothalamic orexin/hypocretincontaining neurons, and reveals dissociable roles of nucleus accumbens and hypothalamus in cortically driven feeding. J Neurosci 33: 18540-18552.

Neisewander JL, Baker DA, Fuchs RA, Tran-Nguyen LT, Palmer A, Marshall JF (2000). Fos protein expression and cocaine-seeking behavior in rats after exposure to a cocaine self-administration environment. J Neurosci 20: 798-805.
O'Brien CP, Childress AR, McLellan AT, Ehrman R (1992). Classical conditioning in drug-dependent humans. Ann NY Acad Sci 654: 400-415.

Pecina S, Berridge KC (2005). Hedonic hot spot in nucleus accumbens shell: where do mu-opioids cause increased hedonic impact of sweetness? J Neurosci 25: 11777-11786.

Perry AN, Westenbroek C, Becker JB (2013). The development of a preference for cocaine over food identifies individual rats with addiction-like behaviors. PLoS ONE 8: e79465.

Pickens CL, Airavaara M, Theberge F, Fanous S, Hope BT, Shaham Y (2011). Neurobiology of the incubation of drug craving. Trends Neurosci 34: 411-420.

Pickens CL, Cifani C, Navarre BM, Eichenbaum H, Theberge FR, Baumann $\mathrm{MH}$ et al (2012). Effect of fenfluramine on reinstatement of food seeking in female and male rats: implications for the predictive validity of the reinstatement model. Psychopharmacology (Berl) 221: 341-353.

Prendergast BJ, Onishi KG, Zucker I (2014). Female mice liberated for inclusion in neuroscience and biomedical research. Neurosci Biobehav Rev 40: 1-5.

Preston KL, Umbricht A, Epstein DH (2002). Abstinence reinforcement maintenance contingency and one-year follow-up. Drug Alcohol Depend 67: 125-137.

Rawson RA, Marinelli-Casey P, Anglin MD, Dickow A, Frazier Y, Gallagher C et al (2004). A multi-site comparison of psychosocial approaches for the treatment of methamphetamine dependence. Addiction 99: 708-717.

Reichel CM, Chan CH, Ghee SM, See RE (2012). Sex differences in escalation of methamphetamine self-administration: cognitive and motivational consequences in rats. Psychopharmacology (Berl) 223: 371-380.

Reichelt AC, Abbott KN, Westbrook RF, Morris MJ (2016). Differential motivational profiles following adolescent sucrose access in male and female rats. Physiol Behav 157: 13-19.

Roll JM (2007). Contingency management: an evidence-based component of methamphetamine use disorder treatments. Addiction 102: 114-120.

Roll JM, Chudzynski J, Cameron JM, Howell DN, McPherson S (2013). Duration effects in contingency management treatment of methamphetamine disorders. Addict Behav 38: $2455-2462$.

Roth ME, Carroll ME (2004). Sex differences in the acquisition of IV methamphetamine self-administration and subsequent maintenance under a progressive ratio schedule in rats. Psychopharmacology (Berl) 172: 443-449.

Scheyer AF, Loweth JA, Christian DT, Uejima J, Rabei R, Le T et al (2016). AMPA receptor plasticity in accumbens core contributes to incubation of methamphetamine craving. Biol Psychiatry 80: 661-670.

Self DW, Choi KH, Simmons D, Walker JR, Smagula CS (2004). Extinction training regulates neuroadaptive responses to withdrawal from chronic cocaine self-administration. Learn Mem 11: 648-657.

Shaham Y, Shalev U, Lu L, De Wit H, Stewart J (2003). The reinstatement model of drug relapse: history, methodology and major findings. Psychopharmacology (Berl) 168: 3-20.

Shalev U, Morales M, Hope B, Yap J, Shaham Y (2001). Timedependent changes in extinction behavior and stress-induced reinstatement of drug seeking following withdrawal from heroin in rats. Psychopharmacology 156: 98-107.

Shepard JD, Bossert JM, Liu SY, Shaham Y (2004). The anxiogenic drug yohimbine reinstates methamphetamine seeking in a rat model of drug relapse. Biol Psychiatry 55: 1082-1089.

Silverman K, DeFulio A, Sigurdsson SO (2012). Maintenance of reinforcement to address the chronic nature of drug addiction. Prev Med 55: S46-S53.

Stewart J, Woodside B, Shaham Y (1996). Ovarian hormones do not affect the initiation and maintenance of intravenous self- 
administration of heroin in the female rat. Psychobiology 24: 115-159.

Stitzer M, Petry N (2006). Contingency management for treatment of substance abuse. Annu Rev Clin Psychol 2: 411-434.

Theberge FR, Li X, Kambhampati S, Pickens CL St, Laurent R, Bossert JM et al (2013). Effect of chronic delivery of the Toll-like receptor 4 antagonist (+)-naltrexone on incubation of heroin craving. Biol Psychiatry 73: 729-737.

Thiel KJ, Painter MR, Pentkowski NS, Mitroi D, Crawford CA, Neisewander JL (2012). Environmental enrichment counters cocaine abstinence-induced stress and brain reactivity to cocaine cues but fails to prevent the incubation effect. Addict Biol 17: $365-377$.
Vandaele Y, Cantin L, Serre F, Vouillac-Mendoza C, Ahmed SH (2016). Choosing under the influence: a drug-specific mechanism by which the setting controls drug choices in rats. Neuropsychopharmacology 41: 646-657.

Venniro M, Caprioli D, Shaham Y (2016). Animal models of drug relapse and craving: from drug priming-induced reinstatement to incubation of craving after voluntary abstinence. Prog Brain Res 224: $25-52$.

Wikler A (1973). Dynamics of drug dependence. Implications of a conditioning theory for research and treatment. Arch Gen Psychiatry 28: 611-616.

Wolf ME (2016). Synaptic mechanisms underlying persistent cocaine craving. Nat Rev Neurosci 17: 351-365.

Supplementary Information accompanies the paper on the Neuropsychopharmacology website (http://www.nature.com/npp) 